\section{An interesting case of deprescribing in a woman with dementia who regained her ability to play the piano following withdrawal of psychotropic medicines}

Bannerjee's review in 2009 confirmed concerns over the use of antipsychotic drugs to treat the behavioural and psychological symptoms of dementia (BPSD) in older people. ${ }^{1}$ Antipsychotic drugs are associated with an increased risk of stroke and overall greater mortality when used in this population. ${ }^{2}$ The cerebrovascular risk is increased further in vascular dementia. ${ }^{3}$ With the exception of risperidone, antipsychotic drugs prescribed for BPSD are being used outside the product licence. The National Institute for Health and Clinical Excellence (NICE) recommends that antipsychotic medication should not be used first line in the management of mild BPSD, but may be offered first line for managing severe symptoms. ${ }^{3}$ Risperidone has marketing authorisation for the short-term treatment (up to 6 weeks) of persistent aggression in patients with moderate to severe Alzheimer's dementia unresponsive to nonpharmacological approaches and when there is a risk of harm to self or others. ${ }^{4}$ The risks and benefits of treatment should be discussed with the patient and their carers taking into consideration the accessible information standard and informed consent to treatment with off-label medicines. ${ }^{35} 6$

We report a case of an 87-year-old woman, EO, with vascular dementia admitted to an older adult psychiatry inpatient unit in May 2015 following disruptive and aggressive behaviour together with disinhibition, which had continued for 3-4 months at the care home where she had lived for 8 months. No specific triggers for this behaviour had been identified. Psychotropic medicines were prescribed over a 3-month period before admission.

On admission, EO's current medication taken orally was promethazine $25 \mathrm{mg}$ once a day, nitrazepam $5 \mathrm{mg}$ at night, trazodone $100 \mathrm{mg}$ twice a day, amisulpride $25 \mathrm{mg}$ in the morning and $50 \mathrm{mg}$ at night, plus lorazepam when required.

We were informed by her family that she had been a very active person. She enjoyed painting and music and had been a talented piano player. She was still playing the piano when she went to live in the care home. However, by the time she was admitted to the inpatient unit, she was no longer able to do so.

On admission, EO presented as having the appearance of being heavily sedated and difficult to arouse. She was unable to swallow, keeping her food in her mouth, and was drooling saliva. Her medication was being administered in liquid form. She was sitting slumped in a chair and was hardly able to participate in any meaningful conversation. She was unable to walk independently.

EO's medication was reviewed, with the deprescribing of psychotropic medication being a priority.

Promethazine, nitrazepam, trazodone and amisulpride can all cause sedation. Benzodiazepines, both lorazepam and nitrazepam, in addition to being associated with disinhibition and confusion, may also be associated with the paradoxical effect of increased agitation and aggression. ${ }^{7}$ The long-acting benzodiazepine, nitrazepam, can cause a hangover effect, especially in older people, contributing to tiredness the following day. The anticholinergic effects of promethazine, trazodone and amisulpride can cause confusion and cognitive impairment. ${ }^{8}$ Psychotropic polypharmacy (polyprescribing) can increase the anticholinergic burden, which can be estimated using an appropriate tool. ${ }^{9}$

All the psychotropic medicines except for trazodone were discontinued. This medicine was chosen to remain because it had been an effective antidepressant in the past for EO and helped her to sleep at night because of its sedative effects. The reduction of medicines took place over 4-8 weeks in a staggered manner. EO became more alert, interacting with staff. Her mobility improved so that she was able to walk independently. Improvements in her quality of life were assessed using behavioural charts, collateral history and observation from relatives, and clinical assessments. The consultant psychiatrist (SS) took her to the piano, letting her touch the keyboard on a daily basis, and this was continued by nursing staff. EO slowly started to play the piano on the ward, with one hand at first. Within a few weeks, much to the delight of her son and daughter, she began to play beautiful pieces from memory. Deprescribing the psychotropic medication played a significant part in enabling EO to play the piano. Her loss of ability to play was predominantly attributed to the prescribed psychotropic medicines. In addition, the positive environment on the ward including explanation, helping and encouragement all contributed to this positive outcome of deprescribing.
EO was discharged on trazodone $100 \mathrm{mg}$ at night back to the care home in July 2015 under the care of the community older people's mental health services. She has not been referred back to the unit for emergence of BPSD and she continues to play the piano.

The key message in this case is that patients on any psychotropic medication need to be reviewed regularly, with medication being continued only if clinically indicated. Deprescribing may be useful in establishing a baseline picture. The withdrawal of psychotropic medication in this case not only improved the quality of life for EO but also for her family who enjoyed listening to her play the piano.

\section{EAHP Statement 6: Education and} Research

\section{Shaheen Shora, ${ }^{1}$ Danielle Adams ${ }^{2}$}

${ }^{1}$ Department of Older Adult Psychiatry, Hertfordshire Partnership NHS Foundation Trust, Radlett, Hertfordshire, UK

${ }^{2}$ Department of Pharmacy, Hertfordshire Partnership NHS Foundation Trust, Radlett, Hertfordshire, UK

Correspondence to Danielle Adams, Department of Pharmacy, Hertfordshire Partnership NHS Foundation Trust, Kingfisher Court, Kingsley Green, Harper Lane, Radlett, Hertfordshire, UK; danielle.adams@hpft.nhs.uk

Contributors DA and SS solely put this case study together. They drafted and revised it, gave final approval for what was submitted, and agree to be accountable for all aspects of the work.

Competing interests None declared.

Provenance and peer review Not commissioned; externally peer reviewed.

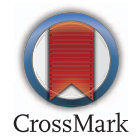

To cite Shora S, Adams D. Eur I Hosp Pharm 2017;24:69-70.

Eur J Hosp Pharm 2017:24:69-70. doi:10.1136/ejhpharm-2016-001072

\section{REFERENCES}

1 Bannerjee S. The use of antipsychotic medication for people with dementia: time for action. A report for the Minister of State for Care Services. Department of Health. November 2009. http://www.rcpsych.ac.uk/pdf/ Antipsychotic\%20Bannerjee\%20Report.pdf

2 Taylor D, Paton C, Kapur S. The Maudsley prescribing guidelines in psychiatry. 12th edn. Wiley, 2015.

3 NICE guidelines [CG42] Published date: November 2006 Last updated: May 2016 Dementia: supporting people with dementia and their carers in health and social care. https://www.nice.org.uk/Guidance/cg42

4 Medicines.org.uk. (September 2015) RisperidoneSummary of Product Characteristics (SPC) - (eMC). http://www.medicines.org.uk/emc/medicine/24423 (accessed 07/10/2016) 
5 NHS England. Accessible Information Standard. https:/l www.england.nhs.uk/ourwork/patients/accessibleinfo/ (accessed 07/10/2016).

6 Sokol D. Update on the UK law on consent. BMJ 2015;350:h1481.

7 Joint Formulary Committee. British National Formulary. 70th edn. London: BMJ Group and Pharmaceutical Press, 2016.

8 NICE Eyes on Evidence, October 2015. Drugs with anticholinergic effects and risk of cognitive impairment, falls and all-cause mortality. https://www. nice.org.uk/Media/Default/newsletter/eyes-onevidence-october-2015.pdf

9 NHS Scotland Polypharmacy Guidance March 2015. http://www.sign.ac.uk/pdf/polypharmacy_guidance.pdf (accessed 06/10/2016) 